\title{
Cigarette Smoking among Adolescents aged 13-15 in Viet Nam and Correlates of Current Cigarette Smoking: Results from GYTS 2014 Data
}

\author{
Le Thi Huong ${ }^{1}$, Nga Thi Thu Vu' ${ }^{1 *}$, Nguyen Ngoc Dung ${ }^{1}$, Le Thi Thanh Xuan ${ }^{1}$, \\ Kim Bao Giang ${ }^{1}$, Phan Thi Hai ${ }^{2}$, Doan Thu Huyen ${ }^{2}$, Luong Ngoc Khue ${ }^{3}$, Nguyen \\ Tuan Lam ${ }^{4}$, Hoang Van Minh ${ }^{5}$, Pham Thi Quynh Nga ${ }^{4}$
}

\begin{abstract}
The aim of this paper is to report the rate of current and ever cigarette smoking and explore correlates of current cigarette smoking among adolescents aged 13-15 in Viet Nam. This analysis was derived from GYTS survey, which comprised of 3,430 adolescents aged 13-15, conducted in 2014 in 13 cities and provinces of Viet Nam. We calculated the weighted rates of current and ever cigarette smoking and reported patterns of smoking behavior. We also performed logistic regression to explore correlates of current cigarette smoking behavior. The weighted rate of ever cigarette smoking was $9.5 \%$ (95\% confidence interval (CI): $8.5 \%-10.5 \%$ ), in which the weighted rate among males $(15.4 \% ; 95 \% \mathrm{CI}: \mathbf{1 3 . 6 \% - 1 7 . 0 \% )}$ was higher than that among females $(4.2 \% ; 95 \%$ CI: $3.3 \%-5.1 \%)$. The weighted rate of current cigarette smoking was relatively low at $2.5 \%$ (95\% CI: $2.0 \%$ 3.0\%) with higher weighted rate among males (4.9\%; 95\% CI: 3.8\%-5.9\%) compared to the corresponding figure among females $(0.2 \% ; 95 \%$ CI: $0.0 \%-0.5 \%)$. Current cigarette smoking was significantly higher among males than females, in students aged 15 versus 13 years old, and in students who had several or all close friends smoking and students with daily observation of smoking at school. For greater smoking reduction outcomes, we recommend that tobacco interventions for adolescents should consider targeting more male students at older ages, establish stricter adherence to school-based banning of cigarette smoking, engage both smoking and nonsmoking adolescents and empower adolescents to resist peer smoking influence as well as changing their norms or beliefs towards smoking benefits.
\end{abstract}

Keywords: Cigarette smoking - adolescents - Viet Nam - correlates - GYST 2014

Asian Pac J Cancer Prev, 17 Tobacco Prevention and Control in Vietnam Suppl, 17-23

\section{Introduction}

Tobacco smoking has been considered as one of the biggest global public health issues in recent years. Smoking of tobacco products was found associated with higher risk of various acute and chronic respiratory conditions (Bates et al., 2007; Lin et al., 2007; Forey et al., 2011; Ilmarinen et al., 2015; Torres et al., 2015). Tobacco smoking was also confirmed to lead to different cancers (Giovannucci, 2001; Sasco et al., 2004). There were also evidences of tobacco smoking associated with other noncommunicable diseases such as cerebrovascular disease (Shiue, 2015) and coronary heart diseases (Grundy et al., 1987). World Health Organization (WHO) estimated that smoking kills approximately 6 million annually, in which 600.000 deaths were caused by passive smoking; $5 \%$ of communicable disease-related deaths and $14 \%$ of non-communicable disease-related deaths among people from 30 years of age were attributable to tobacco smoking (World Health Organization, 2012).

Smoking tobacco products among adolescents has also been of great concerns. Prevalence of ever cigarette smoking among adolescents has been found prevalent, but varied by settings: $35.6 \%$ of adolescents in grade 7 and 8 in Jordan (Al-Sheyab et al., 2014); 21.8\% of school-aged adolescents aged 11-17 in Sudan and South Sudan (Atari, 2014); $22 \%$ of secondary school adolescents in the UK (Jawad et al., 2014); 20\% of secondary and 32\% of high school adolescents in Korea (Park and Kim, 2015). In other parts of Asia, smoking rate was found to be 5.4\% (Rao et al., 2014) in South Asia countries and ranged from $5 \%$ to $20 \%$ in South East Asian countries (Sirichotiratana et al., 2008).

Smoking among adolescents would result in negative

${ }^{1}$ Institute of Preventive Medicine and Public Health, Hanoi Medical University, ${ }^{2}$ Viet Nam Steering Committee on Smoking and Health, ${ }^{3}$ Viet Nam Administration for Clinical Practice Management, Viet Nam Ministry of Health, ${ }^{4}$ World Health Organization Office in Viet Nam, ${ }^{5}$ Hanoi School of Public Health, Hanoi, Viet Nam *For correspondence: vuthunga@hmu.edu.vn 
physical, psychological and studying outcomes. Smoking was found associated with worsen self-rated health (Wang et al., 2012), depressive symptoms (Yue et al., 2015), suicidal behaviors (Park and Kim, 2015) and dropout of school (Svansdottir et al., 2015). Recent studies reported various factors associated with smoking at adolescent age, including early life-stressful events (Iakunchykova et al., 2015; So and Yeo, 2015), consuming alcohol and other drugs, having low academic results, having parental education of secondary or lower and family approval of smoking behaviors (So and Yeo, 2015), cigarettes availability (Roberts et al., 2015), peers and parental smoking behaviors (Madarasova Geckova et al., 2005; Van Minh et al., 2011), having more pocket-money (Kumar et al., 2014) and reaching an older age (Jawad et al., 2014). Given that the majority of adult smokers (90\%) started their smoking at adolescent age (US Department of Health and Human services, 2012), prevention of tobacco smoking among adolescents is, therefore, crucial to prevent future smoking and its associated adverse health conditions, social and psychological harms.

During the past decade, Viet Nam has shown its strong commitment to tobacco control and prevention. On 11st November, 2004, Viet Nam ratified the WHO Framework Treaty for Tobacco Control (FTCT); on 18th June, 2012, Viet Nam National Assembly approved the Law on Tobacco Prevention and Control; on 25th January 2013, Viet Nam's Prime Minister signed the National Strategy for Tobacco Prevention and Control to 2020. Despite these efforts, smoking rates among adults in Viet Nam still remained high. Current smoking prevalence was found to be $23.8 \%$ with higher reported prevalence of men (47.4\%) than that of women (1.4\%) (Tran et al., 2013). A recent study included more than 14,000 people recruited from eight provinces reported the ever rate of smoking among Vietnamese as $74.9 \%$ for men and $2.6 \%$ for women (Bui et al., 2015). However, the smoking rate among adolescents was reported at a relatively low level. The analysis from the Global Youth Tobacco Survey (GYTS) 2007 data from 9 provinces found a total rate of cigarette smoking at $3.9 \%$, with the higher correspondence rate for boys (5.9\%) compared to girls (1.2\%) (Van Minh et al., 2011).

This analysis of GYTS 2014 data aims to report the rate of current and ever cigarette smoking in the last 30 days and assess associated correlates of current cigarette smoking among adolescents aged 13 to 15 in Viet Nam. We analyzed the effects of identified correlates of cigarette smoking in previous studies such as the parent's education and occupation, having parents or close friends who smoked, exposure to pro-tobacco advertisement. We also assessed the exposure to anti-tobacco messages, observed smoking behaviors in schools and assessed how the belief in the benefits gained from smoking affects cigarette smoking rates of adolescents in Viet Nam.

\section{Materials and Methods}

\section{Data source}

The data were derived from the GYTS 2014 which was conducted in 13 cities and provinces in Viet Nam. Detail description of the survey methods could be found in the methodology paper of Kim et al, which is also published in this special issue. This analysis focused on 3430 adolescents aged 13-15.

\section{Measurement}

GYTS survey used a standardized, self-administered questionnaire with optional questions added by individual country (Warren et al., 2008). Basically, the questionnaire contained 76 questions covering sections of demographic information, smoking behaviors, smoking cessation, accessibility and availability of tobacco products, exposure to secondhand smoking, exposure to anti-tobacco messages, exposure to pro-tobacco advertisement, knowledge and attitude to smoking and lastly, implementation of anti-smoking regulations at schools. For the purpose of this analysis, the following new variables were generated from the final GYTS 2014 questionnaire for Viet Nam:

Region of residency: Based on the geographical location of the school, the participants were categorized into 1-living in Northern region, 2- living in Central region and 3-living in Southern region.

Weekly pocket-money: was categorized into 1-having no weekly pocket money, 2- having weekly pocket money under 20,000 VND (equivalent to approximately US\$0.99), and 3- having weekly pocket money from 20,000 VND to 50,000 VND and 4-having weekly pocket money over 50,000 VND.

Occupation of father/mother: was categorized into 3-level variable in which 1 corresponds to government officer, 2- farmer and 3-other occupations.

Education of father/mother: was categorized into 3-level variable in which 1 corresponds to below primary schooling, 2- primary and secondary schooling and 3-high school and higher schooling.

Exposure to pro-tobacco/cigarette advertisement: The participants were categorized as having exposure to tobacco/cigarette advertisement if they answered Yes for any of the following questions: a) During the past 30 days, did you see any people using tobacco when you watched $\mathrm{TV}$, videos, or movies?; b) During the past 30 days, did you see any advertisement or promotion on tobacco products at points of sale such as stores, shops...?; c) Do you have anything with a tobacco advertisement on it?; d) Has any person working for a tobacco company ever offered you a free tobacco product?; e) During the past 30 days, have you seen any advertisement on tobacco products at sport events, concerts, community events or social gatherings?; f) During the past 30 days, have you seen any advertisement on tobacco products on the internet?

Exposure to anti-tobacco message: The participants were categorized as having exposure to anti-tobacco message if they answered Yes for the question "During the past 30 days, have you seen or heard any media messages on tobacco control on television, radio, internet, pane, poster, newspapers, magazines or movies?"

Parental smoking: The participants were categorized into 0-having none of their parents smoked, 1- having either mother or father smoked and 2-having both parents smoked.

Close friends smoking: The participants were 
Cigarette Smoking among Adolescents Aged 13-15 in Viet Nam and Correlates of Current Cigarette Smoking: GYTS 2014

categorized into 0-having no close friends smoked, 1-having several close friends smoked and 2 having all close friends smoked.

Having observation of smoking at school: The participants were categorized into 0-No observations of smoking at schools, 1- Occasional observations of smoking at school and 2-Daily observations of smoking at school.

Studying at schools with smoking regulations: The participants were grouped into school-based smoking regulations if they answered their schools fully or partially implemented smoking bannings on teachers and students.

Believing in the benefits of smoking: The participants were categorized as believing in the benefits of smoking if they answered yes for any of the following questions: i) believe that smoking students have more friends; ii) believe that smoking makes people look more attractive and iii) smoking helps people feel more comfortable in social events.

\section{Analysis}

The data were managed by Center for Disease Control and Prevention (CDC, Atlanta, US). We performed descriptive and analytic analysis by STATA 13.1 (Stata Corp, College Station, TX, USA). We reported weighted rates of current cigarette smoking or ever cigarette smoking and patterns of cigarette smoking behaviors with their $95 \%$ Confidence Interval (95\% CI). Detail descriptions of the calculation of the weight could be found in the methodology paper of Kim et al. We then assessed possible correlates of current cigarette smoking during the last 30 days by univariate logistic regression. All potential independent variables with $\mathrm{p}$ value smaller or equal to 0.25 were entered the base multivariate logistic regression model. We followed procedure previously suggested (Hosmer, 2013) to build up the final multivariate logistic regression model which contained independent variables of current cigarette smoking with $p$ value smaller than 0.05 . Finally, we checked the final model for model specification errors, multicollinearity and Goodness-of-fit (Hosmer, 2013).

\section{Ethical approval}

The GYTS 2014 survey was approved by Ministry of Health, Ministry of Education and Training (MoET) and the Department of Education and Training (DoET) and schools from 13 participated provinces/cities. The survey protocol was approved by the ethical committee of the HMU. All sampled students were orally introduced about the purposes of the survey and their rights to refuse participation in the survey.

\section{Results}

In total, 3430 adolescents aged 13-15 were included in the analysis. Descriptions of demographic characteristics of the sampled participants could be found in the methodology paper of Giang et al. (2016) The sample size for the analysis of each individual variable might be different due to missing values.

The patterns of cigarette smoking can be found in Table 1. The overall weighted rate of ever cigarette smoking was $9.5 \%$ (95\% Confidence Interval (CI): $8.5 \%-10.5 \%$ ), among which the weighted rate among male adolescents was higher $(15.4 \%$; 95\% CI: $13.6 \%-17.0 \%)$ than the correspondence rate of female adolescents $(4.2 ; 95 \% \mathrm{CI}$ :

Table 1. Patterns of Cigarette Smoking among Adolescents aged 13-15 in Viet Nam, GYTS 2014 Data

\begin{tabular}{lccc}
\hline \multirow{2}{*}{ Characteristics } & Overall weighted rate & Male weighted rate & Female weighted rate \\
\cline { 2 - 4 } & $\%(95 \% \mathrm{CI})$ & $\%(95 \% \mathrm{CI})$ & $\%(95 \% \mathrm{CI})$ \\
\hline Rate of ever cigarette smoking $(\mathrm{N}=3368)$ & $9.5(8.5-10.5)$ & $15.4(13.6-17.1)$ & $4.2(3.3-5.1)$ \\
Rate of current cigarette smoking $(\mathrm{N}=3404)$ & $2.5(2.0-3.0)$ & $4.9(3.8-5.9)$ & $0.2(0.0-0.5)$ \\
Smoking location (N=232) & & & \\
At home & $24.5(19.2-30.8)$ & $25.2(19.4-32.2)$ & $22.0(11.6-37.9)$ \\
At school & $10.2(6.9-14.8)$ & $10.0(6.6-15.0)$ & $6.9(2.1-20.3)$ \\
At workplace & $1.9(0.6-5.5)$ & $1.2(0.4-3.7)$ & $5.4(0.8-3.0)$ \\
At friend's house & $15.8(11.5-21.4)$ & $16.5(11.7-22.9)$ & $12.8(5.6-26.4)$ \\
At social events & $1.4(0.5-3.7)$ & $1.7(0.6-4.4)$ & $0(0.0-0.0)$ \\
At public places & $6.4(3.9-10.4)$ & $6.4(3.7-10.9)$ & $6.7(2.0-20.2)$ \\
Others & $39.8(33.0-47.0)$ & $38.9(31.6-46.8)$ & $46.2(29.5-63.7)$ \\
Start age of smoking (years old) $(\mathrm{N}=260)$ & $12.6(9.0-17.3)$ & $12.9(8.9-18.2)$ & $11.1(4.9-23.2)$ \\
Equal or under 10 & $87.4(82.7-91.0)$ & $87.1(81.8-91.1)$ & $88.9(76.8-95.1)$ \\
Over 10 & & & $0(0.0-0.0)$ \\
Smoking consumption per day (cigarettes/day) $(\mathrm{N}=79)$ & $87.6(76.7-93.8)$ & $32.1(4.9-81.4)$ \\
Equal of less than 5 & $83.5(72.1-90.8)$ & $5.8(2.0-16.0)$ & $67.9(18.6-95.1)$ \\
From 6 to 10 & $7.1(2.8-16.5)$ & $6.6(2.6-15.7)$ & $86.4(35.8-98.6)$ \\
More than 10 & $9.4(4.2-19.9)$ & & $0(0.0-0.0)$ \\
Number of smoking days per month (N=76) & $61.7(49.2-72.7)$ & $60.4(47.7-71.9)$ & $13.6(1.4-64.2)$ \\
From 5 days of less & $13.4(6.9-24.4)$ & $14.1(7.3-25.5)$ & $25.5(16.2-37.8)$ \\
From 6 to 9 days & $24.9(15.9-36.9)$ & & \\
From 10 days or more & & & \\
\hline
\end{tabular}


Table 2. Descriptive Statistic of Exposure to Either Pro-tobacco or Anti-tobacco Environment and Belief in Smoking Benefits among Adolescents Aged 13-15 in Viet Nam, GYTS 2014 Data

\begin{tabular}{|c|c|c|}
\hline Characteristic & $\mathrm{n} / \mathrm{N}$ & $\begin{array}{l}\text { Weighted rate } \\
\text { (95\% CI) }\end{array}$ \\
\hline $\begin{array}{l}\text { Exposure to pro-tobacco } \\
\text { advertisement }\end{array}$ & $2823 / 3430$ & $81.4(79.9-82.8)$ \\
\hline $\begin{array}{l}\text { Exposure to anti-tobacco } \\
\text { message }\end{array}$ & $2922 / 3412$ & $84.7(83.3-86.0)$ \\
\hline \multicolumn{3}{|l|}{ Parental smoking } \\
\hline $\begin{array}{l}\text { Having none of parents } \\
\text { smoke }\end{array}$ & $1936 / 3371$ & $55.5(53.7-57.3)$ \\
\hline $\begin{array}{l}\text { Having either mother or } \\
\text { father smoke }\end{array}$ & $1353 / 3371$ & $42.0(40.2-43.8)$ \\
\hline $\begin{array}{l}\text { Having both parents } \\
\text { smoke }\end{array}$ & $82 / 3371$ & $2.5(1.9-3.1)$ \\
\hline \multicolumn{3}{|l|}{ Close friend smoke } \\
\hline $\begin{array}{l}\text { Having no close friend } \\
\text { smoke }\end{array}$ & $2347 / 3412$ & $67.0(65.3-68.7)$ \\
\hline $\begin{array}{l}\text { Having several close } \\
\text { friend smoke }\end{array}$ & $1007 / 3412$ & $31.2(29.7-33.1)$ \\
\hline $\begin{array}{l}\text { Having all close friends } \\
\text { smoke }\end{array}$ & $58 / 3412$ & $1.6(1.3-2.1)$ \\
\hline \multicolumn{3}{|l|}{$\begin{array}{l}\text { Observation of smoking } \\
\text { at schools }\end{array}$} \\
\hline No observation & $890 / 2921$ & $27.8(26.1-29.6)$ \\
\hline Occasional observation & $1604 / 2921$ & $57.1(55.1-59.0)$ \\
\hline Daily observation & $427 / 2912$ & $15.1(13.8-16.6)$ \\
\hline $\begin{array}{l}\text { Study at schools with } \\
\text { smoking regulation }\end{array}$ & $1997 / 3426$ & $55.9(54.1-57.7)$ \\
\hline $\begin{array}{l}\text { Belief in smoking } \\
\text { benefits }\end{array}$ & $1383 / 3428$ & $40.6(38.8-42.4)$ \\
\hline
\end{tabular}

$3.3 \%-5.1 \%)$. The weighted current cigarette smoking was lower, with the overall weighted at $2.5 \%$ (95\% CI: $2.0 \%-$ $3.0 \%$ ); the weighed rate among males was $4.9 \%$ (95\% CI: $3.8 \%-5.9 \%)$ and the weighted rate among females was $0.2 \%$ (95\% CI: $0.0 \%-0.5 \%$ ). The three most common smoking locations for the whole sample was at home (24.5\%; 95\% CI: $19.2 \%-30.8 \%$ ), at friends' house (15.8\%; 95\% CI: $11.5 \%-21.4 \%)$ and at school (10.2\%; 95\% CI: 6.9-14.8). Nearly two fifth of the sampled adolescents smoked in other unidentified places $(39.8 \%$; $95 \% \mathrm{CI}$ : $33.0 \%-47.0 \%)$. This pattern was also true for both male and female adolescents.

Of the total 260 participants who answered the question about the age of smoking initiation, more than one tenth $(12.6 \%)$ started smoking before turning 10 years old. The age of smoking initiation was approximately similar for both males $(12.9 \%$; $95 \%$ CI: $8.9 \%-18.2 \%)$ and females (11.1\%; 95\% CI: $4.9 \%-23.2 \%)$. Of the 79 participants who answered the question about the number of cigarettes they smoked a day, 7.1\% (95\%CI: 2.8-16.5\%) smoked from 6 to 10 cigarettes daily and $9.4 \%$ (95\% CI: $4.2 \%-19.9 \%$ ) smoked more than 10 cigarettes daily. This pattern was true for male participants, however, among females, all smokers smoked more than 5 cigarettes a day and nearly one third (67.9\%; 95\% CI: 18.6\%-95.1\%) smoked more than 10 cigarettes a day. Overall, among current cigarette
Table 3. Univariate Analysis of Potential Correlates of Current Cigarette Smoking among Adolescents aged 13-15 in Viet Nam, GYTS 2014 data

\begin{tabular}{|c|c|c|c|}
\hline \multirow[t]{2}{*}{ Characteristics } & \multicolumn{2}{|c|}{$\begin{array}{l}\text { Univariate logistic } \\
\text { regression }\end{array}$} & \multirow{2}{*}{$\begin{array}{c}\mathrm{P} \\
\text { value }\end{array}$} \\
\hline & OR & $95 \% \mathrm{CI}$ & \\
\hline Being male vs. being female & 20.6 & $7.50-56.45$ & 0.000 \\
\hline Participants age & & & 0.000 \\
\hline 13 years old & 1 & & \\
\hline 14 years old & 3.36 & $1.36-8.31$ & 0.009 \\
\hline 15 years old & 8.56 & $3.64-20.07$ & 0.000 \\
\hline Region & & & 0.882 \\
\hline North & 1 & & \\
\hline Central & 11.08 & $0.63-1.85$ & 0.779 \\
\hline South & 0.92 & $0.52-1.62$ & 0.777 \\
\hline Weekly pocket - money & & & 0.016 \\
\hline No money & 1 & & \\
\hline Under 20000 dong & 1.41 & $0.63-3.20$ & 0.405 \\
\hline 20000-50000 dong & 1.57 & $0.68-3.61$ & 0.287 \\
\hline Over 50000 dong & 2.99 & $1.34-6.65$ & 0.007 \\
\hline Job of father & & & 0.738 \\
\hline Government officer & 1 & & \\
\hline Farmer & 1.19 & $0.49-2.87$ & 0.39 \\
\hline Others & 1.35 & $0.57-3.22$ & 0.5 \\
\hline Education level of father & & & 0.357 \\
\hline Less than primary & 1 & & \\
\hline Primary and secondary & 0.64 & $0.33-1.23$ & 0.178 \\
\hline High school-post graduate & 0.62 & $0.31-1.23$ & 0.174 \\
\hline Job of mother & & & 0.937 \\
\hline Government officer & 1 & & \\
\hline Farmer & 1.07 & $0.47-2.46$ & 0.869 \\
\hline Others & 0.98 & $0.43-2.22$ & 0.965 \\
\hline Education level of mother & & & 0.663 \\
\hline Less than primary & 1 & & \\
\hline Primary and secondary & 0.73 & $0.38-1.42$ & 0.359 \\
\hline High school-post graduate & 0.78 & $0.39-1.56$ & 0.476 \\
\hline $\begin{array}{l}\text { Exposure to tobacco adver- } \\
\text { tisement vs. no exposure }\end{array}$ & 0.95 & $0.53-1.72$ & 0.881 \\
\hline $\begin{array}{l}\text { Exposure to anti-tobacco } \\
\text { message vs. no exposure }\end{array}$ & 0.54 & $0.31-0.93$ & 0.027 \\
\hline Parental smoking & & & 0.003 \\
\hline Neither & 1 & & \\
\hline Either & 1.78 & $1.10-2.87$ & 0.019 \\
\hline Both & 4.82 & $1.95-11.9$ & 0.001 \\
\hline Close friends smoking & & & 0.000 \\
\hline None & 1 & & \\
\hline Several & 19.1 & $8.67-42.2$ & 0.000 \\
\hline All & 121.8 & $47.2-314.5$ & 0.000 \\
\hline $\begin{array}{l}\text { Observation of smoking at } \\
\text { school }\end{array}$ & & & 0.000 \\
\hline None & 1 & & \\
\hline Occasional & 4.38 & $1.54-12.44$ & 0.006 \\
\hline Daily & 18.4 & $6.46-52.38$ & 0.000 \\
\hline $\begin{array}{l}\text { With smoking regulation } \\
\text { vs. without }\end{array}$ & 0.78 & $0.50-1.24$ & 0.299 \\
\hline $\begin{array}{l}\text { Belief in smoking benefits } \\
\text { vs. having no belief }\end{array}$ & 2.2 & $1.38-3.49$ & 0.001 \\
\hline
\end{tabular}


Table 4. Multivariate Analysis of Independent Correlates of Current Cigarette Smoking among Adolescents Aged 13015 in Viet Nam, GYTS 2014 Data

\begin{tabular}{|c|c|c|c|c|c|}
\hline & Base model & Model 2 & Model 3 & Model 4 & Model 5 \\
\hline & $\operatorname{AOR}(95 \% \mathrm{CI})$ & $\operatorname{AOR}(95 \% \mathrm{CI})$ & $\operatorname{AOR}(95 \% \mathrm{CI})$ & $\operatorname{AOR}(95 \% \mathrm{CI})$ & $\operatorname{AOR}(95 \% \mathrm{CI})$ \\
\hline $\begin{array}{l}\text { Being male vs. being } \\
\text { female }\end{array}$ & $\begin{array}{c}18.27 \\
(5.48-60.86) * * *\end{array}$ & $\begin{array}{c}17.91 \\
(5.40-59.48) * * *\end{array}$ & $\begin{array}{c}18.09 \\
(5.50-59.43) * * *\end{array}$ & $\begin{array}{c}17.01 \\
(5.20-55.63) * * *\end{array}$ & $\begin{array}{c}11.55 \\
(4.13-32.35)^{* * *}\end{array}$ \\
\hline \multicolumn{6}{|l|}{ Participants age } \\
\hline 13 years old & 1 & 1 & 1 & 1 & \\
\hline 14 years old & $3.05(1.07-8.74)^{*}$ & $3.02(1.06-8.60)^{*}$ & $2.96(1.05-8.38)^{*}$ & $2.99(1.06-8.48)^{*}$ & $2.25(0.86-5.89)$ \\
\hline 15 years old & $\begin{array}{c}5.84 \\
(2.15-15.85) * * *\end{array}$ & $\begin{array}{c}5.72 \\
(2.12-15.45) * * *\end{array}$ & $\begin{array}{c}5.87 \\
(2.20-15.65) * * *\end{array}$ & $\begin{array}{c}5.82 \\
(2.18-15.50)^{* * *}\end{array}$ & $\begin{array}{c}4.56 \\
(1.86-11.18)^{* * *}\end{array}$ \\
\hline \multicolumn{6}{|l|}{ Weekly pocket - money } \\
\hline No money & 1 & 1 & 1 & NA & NA \\
\hline Under 20000 dong & $2.50(0.92-6.74)$ & $2.45(0.91-6.57)$ & $2.07(0.82-5.28)$ & & \\
\hline 20000-50000 dong & $1.99(0.73-5.44)$ & $1.98(0.72-5.41)$ & $1.74(0.67-4.48)$ & & \\
\hline Over 50000 dong & $2.51(0.93-6.77)$ & $2.54(0.95-6.82)$ & $2.22(0.88-5.63)$ & & \\
\hline $\begin{array}{l}\text { Exposure to anti-tobacco } \\
\text { message vs. no exposure }\end{array}$ & $0.77(0.38-1.54)$ & $0.78(0.39-1.57)$ & NA & NA & NA \\
\hline \multicolumn{6}{|l|}{ Parental smoking } \\
\hline No smoking parents & 1 & 1 & 1 & 1 & NA \\
\hline $\begin{array}{l}\text { Having either smoking } \\
\text { mother or father }\end{array}$ & $0.79(0.44-1.43)$ & $0.79(0.44-1.43)$ & $0.87(0.49-1.55)$ & $0.88(0.50-1.56)$ & \\
\hline $\begin{array}{l}\text { Having both of smoking } \\
\text { parents }\end{array}$ & $2.56(0.70-9.38)$ & $2.28(0.64-8.15)$ & $2.19(0.65-7.34)$ & $2.14(0.67-6.90)$ & \\
\hline \multicolumn{6}{|l|}{ Close friends smoking } \\
\hline $\begin{array}{l}\text { Having no close, smoking } \\
\text { friends }\end{array}$ & 1 & 1 & 1 & 1 & \\
\hline $\begin{array}{l}\text { Having several close, } \\
\text { smoking friends }\end{array}$ & $\begin{array}{l}14.10(4.87- \\
40.85)\end{array}$ & $\begin{array}{c}13.99 \\
(4.83-40.50)^{* * *}\end{array}$ & $\begin{array}{c}14.19 \\
(4.91-40.99) * * *\end{array}$ & $\begin{array}{c}14.23 \\
(4.91-41.27)^{* * *}\end{array}$ & $\begin{array}{c}11.07 \\
(4.89-40.47)^{* * *}\end{array}$ \\
\hline $\begin{array}{l}\text { Having all close, smoking } \\
\text { friends }\end{array}$ & $\begin{array}{c}84.17(23.47- \\
301.83)\end{array}$ & $\begin{array}{c}84.72 \\
(23.66- \\
303.35)^{* * *}\end{array}$ & $\begin{array}{c}79.75 \\
(22.56- \\
281.96)^{* * *}\end{array}$ & $\begin{array}{c}82.80 \\
(23.43- \\
292.61)^{* * *}\end{array}$ & $\begin{array}{c}73.44 \\
(21.68- \\
248.71)^{* * *}\end{array}$ \\
\hline \multicolumn{6}{|l|}{$\begin{array}{l}\text { Observation of smoking at } \\
\text { school }\end{array}$} \\
\hline $\begin{array}{l}\text { Having no observation of } \\
\text { smoking at school }\end{array}$ & 1 & 1 & 1 & 1 & \\
\hline $\begin{array}{l}\text { Having occasional } \\
\text { observation of smoking at } \\
\text { school }\end{array}$ & $1.28(0.41-3.40)$ & $1.27(0.41-3.97)$ & $1.30(0.42-4.00)$ & $1.25(0.41-3.82)$ & $1.30(0.43-3.94)$ \\
\hline $\begin{array}{l}\text { Having daily observation } \\
\text { of smoking at school }\end{array}$ & $3.00(0.95-9.50)$ & $3.08(0.98-9.67)$ & $3.05(0.98-9.50)$ & $2.95(0.95-9.13)$ & $3.11(1.02-9.54)^{*}$ \\
\hline $\begin{array}{l}\text { Belief in smoking benefits } \\
\text { vs. having no belief in } \\
\text { smoking benefits }\end{array}$ & $1.09(0.62-1.92)$ & NA & NA & NA & NA \\
\hline
\end{tabular}

$* * *, \mathrm{p}<0.001 ; *, \mathrm{p}<0.05$

smokers $(n=76)$, nearly one fourth $(24.9 \%$; $95 \%$ CI: $15.9 \%-36.9 \%$ ) smoked ten or more days a month. While this pattern was true for male participants, among female participants, the majority of smokers smoked five days or less a month (86.4\%; 95\% CI: 35.8\%-98.6\%). However, there was only $13.6 \%$ of current female cigarette smokers who smoked ten or more days a month.

Table 2 presents descriptive statistics of exposure to either anti-tobacco or pro-tobacco environment and the belief in smoking benefits. The majority of sampled adolescents had exposure to either pro-tobacco advertisement $(81.4 \%$; 95\% CI: $79.9 \%-82.8 \%)$ or antitobacco messages $(84.7 \%$; 95\% CI: $83.3 \%-86.0 \%)$. Nearly half of the participants $(44.5 \%)$ had either mother or father or both parents who smoked. Nearly one third of the participants had close friends who smoked (32.8\%). While $55.9 \%$ (95\% CI: $54.1 \%-57.7 \%$ ) of participants studied in schools with smoking regulation, there were still over two third of participants who had occasional (57.1\%; 95\% CI: $55.1-59.0)$ or daily (15.1\%; 95\% CI: 13.8-16.6) observation of smoking at their schools. In relation to the belief in smoking benefits, $40.65 \%$ (95\% CI: 38.8-42.4) answered yes to any or all of the corresponding questions. The results of the univariate analysis of correlates of current cigarette smoking among participants were presented in Table 3. In univariate analysis, potential correlates of current cigarette smoking included sex, weekly pocket- money, exposure to anti-tobacco message, 
having parents who smoked, having close friends who smoked, observation of smoking at school and the belief in the benefits of smoking. However, in the final multivariate logistic regression model (Table 4), there were only four variables that remained significant correlates of current cigarette smoking including sex (being males versus females) (AOR: 11.55; 95\% CI: 4.13-32.35); participant age (being 15 years old versus being 13 years old) (AOR: 4.56; 95\% CI: 1.86-11.18); having close friends who smoked (having several close friends who smoked versus having no close friends who smoked (AOR: 11.07; 95\% CI: 4.89-40.47) or having all close friends who smoked (AOR: 73.44; 95\% CI: 21.68-248.71)) and having daily observations of smoking at school versus having no observations (AOR: 3.11; 95\% CI:1.02-9.54).

\section{Discussion}

This analysis of the third GYTS data in Viet Nam found relatively low rates of ever and current cigarette smoking rates among schooling adolescents aged 13-15 in Viet Nam. We found that the current cigarette smoking rate was $2.5 \%$, compared to the corresponding rate of $3.9 \%$ in the previous Viet Nam's 2007 GYTS data (Van Minh et al., 2011). This decreased rate of current cigarette smoking among adolescents may indicate an effectiveness of current anti-tobacco interventions in Viet Nam. This promising result might suggest that Viet Nam could eliminate cigarette smoking among adolescents in the next period. The following paragraphs discuss possible implications from the findings of our analysis to Viet Nam's anti-smoking interventions for adolescent.

We found that cigarette smoking was more prevalent among male participants than female students and among participants aged 15 compared to adolescents aged 13 . Our findings were similar to the finding of Viet Nam's GYTS 2007(Van Minh et al., 2011) and recent studies in various settings, including Malaysia (Tee and Kaur, 2014), Marroco (Shaikh, 2014), Nigeria (Okagua et al., 2015) or GYTS 2007 data from South East Asian countries (Sirichotiratana et al., 2008). Our results suggest that antismoking interventions for adolescents should specifically target male adolescents in their senior grades of secondary schools and early high schools, when adolescents experience lots of physical and psychological transitions during their puberty period. We found that cigarette smoking was significantly higher among participants who observed smoking behaviors daily at their schools, similar to the findings of a recent study among primary school children in China (Huang et al., 2013). The Vietnamese government has already issued penalties for smoking at schools or child-care facilities (Government of Socialist Republic of Viet Nam, 2013). Meanwhile, only less than one third $(27.8 \%$; $95 \%$ CI: $26.1 \%-29.6 \%)$ of this 2014 GYTS sample reported observation of no smoking at their school. From these findings, we would like to recommend stricter adherence to school-based smoking banning and broader disseminations of the school regulations across the nation.

We found that cigarette smoking was significantly higher in adolescents who have several or all of their close friends smoked. These findings were similar to the finding of Viet Nam's GYTS 2007 (Van Minh et al., 2011) and the findings of GYTS surveys and previous studies in other countries (Madarasova Geckova et al., 2005; Warren et al., 2008; Jawad et al., 2014). Previous studies indicated that peer pressure played a key role in starting and maintaining smoking habits (Filippidis et al., 2015; Subramaniam et al., 2015). In light of these findings, the results of our analysis suggest that anti-tobacco interventions targeting adolescent could consider novel interventions to empower adolescents to resist peer-related smoking influence. A recent qualitative study in Canada reported that young adolescents could influence their friends who smoked to quit smoking (Woodgate and Busolo, 2015). This finding denotes that concurrent with the interventions directly targeting adolescents who smoked, school-based anti-smoking interventions could also try to involve nonsmoking adolescents to help their friends who smoked to stop smoking.

Precautions should be bear in mind in interpreting our results. Though we imposed a standard protocol of recruiting participants and used a common questionnaire which allowed for comparison among participating countries (Warren et al., 2008), the GYTS survey sampled only school-based adolescents, as such, while our sample would be representative for the corresponding adolescents in Viet Nam, generalizations of our findings to the whole adolescent population in Viet Nam could result in possible bias. Further studies are needed to better understand cigarette smoking and other tobacco products use among out-of-school adolescents.

To conclude, Viet Nam should continue its efforts to eliminate cigarette smoking among schooling adolescents. Interventions should target male adolescents at older age and both smoking and non-smoking adolescents. Empowerment of adolescents to resist peer smoking influence might result in greater smoking reduction outcome. Stricter adherence to school-based bannings of smoking behaviors and disseminations of these regulations in school settings are recommended.

\section{Acknowledgements}

We thank the VINACOSH (Vietnam Steering Committee on Smoking and Health) and GYTS team of Vietnam for making these data available. We also thank WHO's Tobacco Free Initiative (TFI) and CDC's Office on Smoking and Health for providing technical assistances. We also acknowledge the financial supports and coordination of the Hanoi School of Public Health and the Tobacco Control Research group of Vietnam Tobacco Control Fund. There were no conflicts of interest declared.

\section{References}

Al-Sheyab N, Alomari MA, Shah S, et al (2014). Prevalence, patterns and correlates of cigarette smoking in male adolescents in northern Jordan, and the influence of waterpipe use and asthma diagnosis: a descriptive crosssectional study. Int J Environ Res Public Health, 11, 9008-23. Atari DO (2014). Gender differences in the prevalence and 
Cigarette Smoking among Adolescents Aged 13-15 in Viet Nam and Correlates of Current Cigarette Smoking: GYTS 2014

determinants of tobacco use among school-aged adolescents (11-17 years) in Sudan and South Sudan. Pan Afr Med J, 18, 118.

Bates MN, Khalakdina A, Pai M, et al (2007). Risk of tuberculosis from exposure to tobacco smoke: a systematic review and meta-analysis. Arch Intern Med, 167, 335-42.

Bui TV, Blizzard L, Luong KN, et al (2015). Declining prevalence of tobacco smoking in Vietnam. Nicotine Tob Res, 17, 831-8.

Filippidis FT, Agaku IT, Vardavas CI (2015). The association between peer, parental influence and tobacco product features and earlier age of onset of regular smoking among adults in 27 European countries. Eur J Public Health, 25, 814-8.

Forey BA, Thornton AJ, Lee PN (2011). Systematic review with meta-analysis of the epidemiological evidence relating smoking to COPD, chronic bronchitis and emphysema. BMC Pulm Med, 11, 36.

Giang KB, Minh HV, Hai PT, et al (2016). Methodology for the Global Youth Tobacco Use survey (GYST), Vietnam, 2014. Asian Pac J Cancer Prev, 17 Tobacco Prevention and Control in Viet Nam Suppl, 11-15.

Giovannucci E (2001). An updated review of the epidemiological evidence that cigarette smoking increases risk of colorectal cancer. Cancer Epidemiol Biomarkers Prev, 10, 725-31.

Grundy SM, Greenland P, Herd A, et al (1987). Cardiovascular and risk factor evaluation of healthy American adults. A statement for physicians by an Ad Hoc Committee appointed by the Steering Committee, American Heart Association. Circulat, 75, 1340-62.

Hosmer DW 2013. Applied Logistic Regression, Hoboken, Hoboken : Wiley.

Huang C, Koplan J, Yu S, et al (2013). Smoking experimentation among elementary school students in China: influences from peers, families, and the school environment. PLoS One, 8, 73048 .

Iakunchykova OP, Andreeva TI, Nordstrom DL, et al (2015). The impact of early life stress on risk of tobacco smoking initiation by adolescents. Addict Behav, 50, 222-8.

Ilmarinen P, Tuomisto LE, Kankaanranta H (2015). Phenotypes, risk factors, and mechanisms of adult-onset asthma. Mediators Inflamm, 2015, 514868.

Jawad M, McIver C, Iqbal Z (2014). Prevalence and correlates of lifetime waterpipe, cigarette, alcohol and drug use among secondary school students in Stoke-on-Trent, UK: a post hoc cross-sectional analysis. J Public Health (Oxf), 36, 615-21.

Kumar V, Talwar R, Roy N, et al (2014). Psychosocial determinants of tobacco use among school going adolescents in Delhi, India. $J$ Addict, 2014, 170941.

Lin HH, Ezzati M, Murray M (2007). Tobacco smoke, indoor air pollution and tuberculosis: a systematic review and metaanalysis. PLoS Med, 4, 20.

Madarasova Geckova A, Stewart R, van Dijk JP, et al (2005). Influence of socio-economic status, parents and peers on smoking behaviour of adolescents. Eur Addict Res, 11, 204-9.

Okagua J, Opara P, Alex-Hart BA (2015). Prevalence and determinants of cigarette smoking among adolescents in secondary schools in Port Harcourt, Southern Nigeria. Int $J$ Adolesc Med Health.

Park S, Kim J (2015). Association between smoking and suicidal behaviors among adolescents in the republic of Korea. $J$ Addict Nurs, 26, 175-83.

Rao S, Aslam SK, Zaheer S, et al (2014). Anti-smoking initiatives and current smoking among 19,643 adolescents in South Asia: findings from the global youth tobacco survey. Harm Reduct J, 11, 8.
Roberts ME, Colby SM, Jackson KM (2015). What predicts early smoking milestones? J Stud Alcohol Drugs, 76, 256-66.

Sasco AJ, Secretan MB, Straif K (2004). Tobacco smoking and cancer: a brief review of recent epidemiological evidence. Lung Cancer, 45, 3-9.

Shaikh MA (2014). Prevalence, correlates, and changes in tobacco use between 2006 and 2010 among 13-15 year Moroccan school attending adolescents. J Pak Med Assoc, 64, 1306-9.

Shiue I (2015). Self and environmental exposures to drinking, smoking, gambling or video game addiction are associated with adult hypertension, heart and cerebrovascular diseases, allergy, self-rated health and happiness: Japanese General Social Survey, 2010. Int J Cardiol, 181, 403-12.

Sirichotiratana N, Sovann S, Aditama TY, et al (2008). Linking data to tobacco control program action among students aged 13-15 in Association of Southeast Asian Nations (ASEAN) member states, 2000-2006. Tob Control, 17, 372-8.

So ES, Yeo JY (2015). Factors associated with early smoking initiation among Korean adolescents. Asian Nurs Res, 9 , 115-9.

Subramaniam M, Shahwan S, Fauziana R, et al (2015). Perspectives on smoking initiation and maintenance: a qualitative exploration among Singapore youth. Int J Environ Res Public Health, 12, 8956-70.

Svansdottir E, Arngrimsson SA, Sveinsson T, et al (2015). Importance of physical health and health-behaviors in adolescence for risk of dropout from secondary education in young adulthood: an 8-year prospective study. Int J Equity Health, 14, 140.

Tee GH, Kaur G (2014). Correlates of current smoking among Malaysian secondary school children. Asia Pac J Public Health, 26, 70-80.

Torres A, Blasi F, Dartois N, et al (2015). Which individuals are at increased risk of pneumococcal disease and why? Impact of COPD, asthma, smoking, diabetes, and/or chronic heart disease on community-acquired pneumonia and invasive pneumococcal disease. Thorax, 70, 984-9.

Tran DT, Kosik RO, Mandell GA, et al (2013). Tobacco control in Vietnam. Public Health, 127, 109-18.

Van Minh H, Hai PT, Giang KB, et al (2011). Effects of individual characteristics and school environment on cigarette smoking among students ages 13-15: A multilevel analysis of the 2007 Global Youth Tobacco Survey (GYTS) data from Vietnam. Glob Public Health, 6, 307-19.

Wang MP, Ho SY, Lo WS, et al (2012). Smoking is associated with poor self-rated health among adolescents in Hong Kong. Nicotine Tob Res, 14, 682-7.

Warren CW, Jones NR, Peruga A, et al (2008). Global youth tobacco surveillance, 2000-2007. MMWR Surveill Summ, 57, 1-28.

Woodgate RL, Busolo DS (2015). A qualitative study on Canadian youth's perspectives of peers who smoke: an opportunity for health promotion. BMC Public Health, 15, 1301.

Yue Y, Hong L, Guo L, et al (2015). Gender differences in the association between cigarette smoking, alcohol consumption and depressive symptoms: a cross-sectional study among Chinese adolescents. Sci Rep, 5, 17959. 